\title{
Um modelo estruturado de competências e maturidade em gerenciamento de projetos
}

\author{
Roque Rabechini JR. \\ Doutor pela Escola Politécnica da USP \\ Marcelo Schneck de Paula Pessôa \\ Prof. do Depto. de Engenharia de Produção da Escola Politécnica da USP.
}

\begin{abstract}
Resumo
Este estudo apresenta um modelo analítico estruturado, que se insere no campo de estudos de gerenciamento de projetos nas organizações. Sua importância decorre de que o ambiente empresarial vem passando por intensas mudanças, nas últimas décadas, reflexo das inúmeras transformações tecnológicas, sociais e políticas, em curso nos mais diversos setores econômicos. É nítida a importância das atividades que se caracterizam pela inovação em qualquer processo de mudança, pois, em geral, são elas que agregam mais valor ao produto ou serviço. Neste sentido, gerenciar melhor todos os recursos de uma organização é fundamental para as empresas que querem ser mais competitivas e progredir. No entanto, conseguir maturidade em gerenciamento de projetos implica em decidir por uma série de ações consistentes, envolvendo desenvolvimento de competências em várias instâncias, e isto leva tempo e tem reflexos em toda a organização. A contribuição deste estudo está, justamente, em entender o processo de obtenção da maturidade em gerenciamento de projetos nas organizações, bem como em propor um modelo referencial para ser adotado por elas.
\end{abstract}

Palavras-chave

Competências em gerenciamento de projetos, maturidade em gerenciamento de projetos, gerenciamento de projetos.

\section{Project management maturity and competences: a structured analytic model}

\begin{abstract}
This study presents a structured analytic model focused on project management applied to enterprise organizations. The vital importance of the topic regarding project management is pointed out, given that current enterprise status in the majority of economic branches undergoes intense technological, social and political transformations. The enterprises are evidently influenced by such transformations, being compelled to constant adjustments so as to accompany the demands for high quality in both products and services. The importance of innovation resulting from changing processes is eminent, since it constitutes the basis for value aggregation to the product or service. In this way, the improvement in management of all the organization resources is fundamental for the progress and the competitive aspect of the enterprises. However, maturity attainment in such a subject implies in ability for making consistent decisions, which can require time to develop a set of skills and, consequently, affect all the enterprise organization. This study contributes in understanding the processes for maturity achievement in project management applied to enterprise organizations. The proposed model intends to be a reference to be adopted by the organizations.
\end{abstract}

Key words

Project management competences, project management maturity, project management. 


\section{INTRODUĈ̣̃O}

Cada vez mais os projetos tendem a crescer em importância para as organizações, e quanto mais alinhados estiverem aos negócios das empresas, certamente, mais vantagens estas obterão na competição (KING, 1993).

Investir na adoção de maturidade em gerenciamento de projetos está sendo uma preocupação estratégica, nas diversas lideranças empresariais. Isto pode ser percebido pelo crescimento de interessados em entender e se profissionalizar em gerenciamento de projetos. As instituições, preocupadas em disseminar a disciplina de gerenciamento de projetos e promover a profissão do gerente de projetos, no mundo, se expandem.

No entanto, administrar projetos com sucesso não tem sido uma prática constante. É muito mais que adotar um guia referencial ou um software de apoio - aliás, isto pode ser uma oportunidade perdida, para quem quiser colher os benefícios da boa gerência.

Este estudo é a síntese do trabalho de doutoramento e orientação dos respectivos autores, onde se propôs um modelo útil para analisar o sistema de gerenciamento de projetos nas organizações, possibilitando a estruturação de ações prospectivas. Através da abordagem de estudo de múltiplos casos, investigou-se a maturidade em gerenciamento de projetos, através da análise das práticas adotadas em três empresas de setores distintos. Os resultados de levantamentos empíricos serão apresentados e discutidos. Inicialmente, serão mostrados dois casos, que foram estudados através da utilização de modelos em gerenciamento de projetos existentes atualmente, e que visam apoiar a análise da argumentação deste trabalho. O terceiro caso será examinado a partir do modelo proposto na tese de doutoramento aqui mencionada.

A principal questão de pesquisa que orientou o estudo foi: Como as empresas podem se estruturar para desenvolver competências, visando atingir maturidade em gerenciamento de projetos?

\section{COMPETÊNCIAS E MATURIDADE EM GERENCIAMENTO DE PROJETOS}

O conceito de projetos tem sido aprimorado nos últimos anos, visando estabelecer um entendimento comum nas organizações que trabalham com este tipo de empreendimento. Para o $\mathrm{PMI}^{\circledR}$ - Project Management Institute, um projeto pode ser definido, em termos de suas caracte- rísticas distintivas, como sendo "um empreendimento temporário feito para criar um produto ou serviço único" (PMI, 2000).

Os conceitos de projeto e gerenciamento de projetos podem ser ampla e profundamente entendidos através, entre outras, da abordagem de fatores críticos.

Os fatores críticos de sucesso foram estudados por Pinto e Sleven (1983 e 1998), que fazem uma abordagem específica voltada ao gerenciamento de projetos.

Partindo do pressuposto que um projeto é considerado sucesso em sua implementação caso atenda a quatro critérios - tempo, custo, eficácia e satisfação do cliente -, Pinto e Slevin (1983 e 1998) estabeleceram o modelo dos dez fatores: missão, suporte gerencial, plano, cliente consultor, questões pessoais, questões técnicas, aceite cliente, comunicação, monitoramento e conciliação.

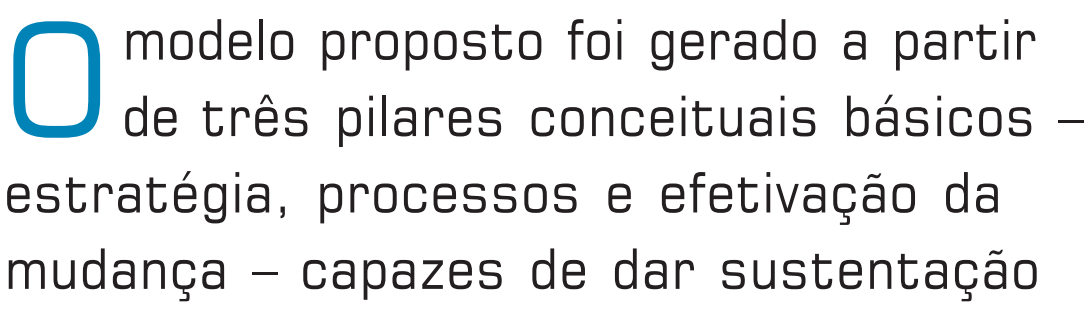
às camadas de competências envolvidas na institucionalização de gerenciamento de projetos: indivíduo, equipes e organização. entendimento das diversas facetas do sucesso em projetos. Neste sentido, o desenvolvimento de competências específicas no âmbito do gerenciamento de projetos passa a ser um elemento de relevada importância. Competência, que para Lê Boterf (1988 e 1994) é um conceito em formação, é uma palavra que vem do latim, competere. O conceito de competência pode ser visto, inicialmente, com a decomposição da palavra em latim: com, cujo significado é conjunto, e petere, cujo significado é esforço. Competência é um conceito pelo qual se definem quais são as atitudes, as habilidades e os conhecimentos necessários para alcançar resultados diferenciados.

\section{Competências em gerenciamento de projetos}

Frame (1999) sugere três tipos de competências em gerenciamento de projetos: as individuais, as de equipe e as da empresa. Estes tipos podem ser vistos como se fossem três vetores. $\mathrm{O}$ primeiro se refere às aptidões $\mathrm{e}$ 
habilidades dos indivíduos na solução de problemas de projetos. De modo geral, este vetor tem sido tratado pela literatura técnica especializada em gerenciamento de projetos através das competências do gerente (MAXIMIANO, 1988, RABECHINI JR., 2001, RABECHINI JR e CARVALHO, 1999, CLELAND, 1999 e CLELAND; IRELAND, 2002).

As competências da equipe, segundo vetor, nesta consideração, estão relacionadas fortemente com a capacidade de resolução de problemas complexos em contexto multidisciplinar. A principal contribuição para este vetor veio do trabalho de Thamhain apud Cleland (1983), em que analisou o desempenho de equipes de projetos, considerando as facilidades e barreiras, os fatores ambientais e estilos de liderança gerencial para sua formação e desenvolvimento. Estas variáveis compõemse em dois grupos distintos de indicadores que podem ser utilizados para estabelecer as bases para identificar as competências em equipes de projetos, bem como medir seu desempenho. O primeiro grupo é formado por elementos com características orientadas às atividades e resultados em projeto, o segundo, orientado às pessoas.

As competências da empresa, por fim, formam o terceiro vetor, que lida com a capacidade de criação de um ambiente que possibilite o envolvimento, tanto do indivíduo quanto das equipes, em tocar seus projetos de forma eficaz. A exploração deste vetor pode ser vista pela abordagem dos modelos de maturidade em gerenciamento de projetos.

\section{MODELOS DE MATURIDADE EM GERENCIAMENTO DE PROJETOS: ABORDAGENS DISTINTAS}

Duas abordagens conceituais/teóricas foram fundamentais no desenvolvimento deste estudo, que serão vistas a seguir.

\section{O modelo de Kerzner}

O modelo proposto por Kerzner (1999) sugere que, para uma empresa alcançar a excelência em gerenciamento de projetos, é necessário galgar cinco níveis, semelhantes ao CMM (SEI,1997), em que cada nível representa um grau diferente de maturidade.

O primeiro nível - linguagem comum - é o nível em que a organização reconhece a importância do gerenciamento de projetos como metodologia útil para atingir sucesso em projetos. Neste nível, em geral a organização sente a necessidade de ter um bom entendimento e conhecimento básico na disciplina, com condições, ao menos, para estabelecer uma terminologia.

O segundo nível - processos comuns - refere-se ao reconhecimento da organização da necessidade de estabelecimento de processos comuns para projetos. Os processos comuns visam repetir o sucesso obtido de um projeto para todos os outros na organização.

O nível três - metodologia singular - é quando a organização reconhece a possibilidade de obter sinergia dada a combinação de várias metodologias dentro de uma única, sendo que seu eixo central é o gerenciamento de projetos.

O quarto nível - Benchmarking - é formado por um processo contínuo de comparação das práticas de gerenciamento de projetos desenvolvidas por uma organização, com outras. O objetivo desta fase é a obtenção de informações que ajudem a organização a melhorar seu desempenho.

Finalmente, no último nível - 5, do melhoramento contínuo - é aproveitada a informação aprendida, advinda do nível anterior (benchmarking) para implementar as mudanças necessárias visando o melhoramento contínuo nos processos de gerenciamento de projetos.

\section{OPM3 - ORGANIZATIONAL PROJECT MANAGEMENT MATURITY MODEL}

A idéia de criar um modelo de maturidade em gerenciamento de projetos que fosse padrão do $\mathrm{PMI}^{\circledR}$ - Project Management Institute, ocorreu em maio de 1998, quando foi constituído o programa OPM3 - Organization Project Management Maturity Model. Através de um Comitê de Padrões foram discutidas as principais capacitações inerentes a um gerenciamento de projetos organizacional (SCHLICHTER, 2001). São elas:

a) padronização e integração de métodos e processos - Esta área foi proposta visando o estabelecimento de uma linguagem comum a ser praticada por todos os envolvidos com gerenciamento de projetos, que será conseguida através da padronização de conceitos, termos, relatórios, gráficos, etc.

b) desempenho e métricas - Esta área propõe o desenvolvimento de medidas de desempenho para os projetos, enfatizando os aspectos do trinômio prazo / custo / qualidade.

c) comprometimento com procedimentos de gerenciamento de projetos - Esta área propõe o estabelecimento de políticas de gerenciamento de projetos acompanhado de metas específicas.

d) priorização de projetos e alinhamento estratégico - Esta área caracteriza-se pela possibilidade de gerar um conjunto de projetos que suportem as estratégias organizacionais.

e) melhoramento contínuo - Esta área visa garantir que as informações das lições aprendidas sejam armazenadas e acessíveis por equipes para minimizar e evitar as possíveis falhas em projetos. 
f) estabelecimento de critérios de sucesso - Esta área busca identificar os projetos com adequação de valor para as estratégias organizacionais.

g) pessoas e suas competências - Esta área visa criar mecanismos formais para avaliação de competências dos recursos das equipes de projetos.

h) alocação pessoal - Esta área deverá interpretar as priorizações dos projetos segundo as estratégias organizacionais para alocação adequada de recursos.

i) aspectos organizacionais - Esta área propõe a estruturação das equipes de projetos considerando-se as formas organizacionais existentes.

j) equipes - Esta área envolve a formação de uma cultura baseada em equipes de projetos, considerando-se o estabelecimento de níveis de inovação e criatividade de trabalhos conjuntos.

\section{AS EMPRESAS QUE CONSTITUÍRAM OS CASOS: PRÁTICAS PERCEBIDAS E MATURIDADE EM GERENCIAMENTO DE PROJETOS}

Serão apresentados, a seguir, os resultados dos dois casos selecionados que configuraram diagnósticos distintos sobre gerenciamento de projetos, seguidos de respectivas análises, enfocando os modelos adotados.

Os dois casos foram tratados com abordagens teóricas distintas, que constituem parte da literatura sobre avaliação e requisitos para institucionalização de gerenciamento de projetos nas organizações. Cada caso visa, portanto, representar um modelo teórico.

\section{Estudo do caso A}

O caso A refere-se a uma organização do ramo das telecomunicações cuja missão declarada foi: entender as necessidades e as oportunidades de seus clientes, provendo soluções de comunicações melhores do que quaisquer de seus concorrentes.

O modelo adotado para o desenvolvimento deste caso A foi elaborado por Kerzner (1999 e 2000), enfatizando as fases do nível dois de maturidade.

Os resultados do diagnóstico feito na organização representante do caso A revelaram que já foi percorrido um bom caminho na direção do gerenciamento de projetos, porém, notou-se a ausência do desenvolvimento de uma série de ações visando atingir a maturidade.

A avaliação das variáveis propostas por Kerzner (2000) mostra que a organização atingiu um nível de maturidade de 50,4\%, revelando, assim, a possibilidade de desenvolvimento de ações rumo ao gerenciamento de projetos. $\mathrm{O}$ modelo mostrou que os índices de cada fase oscilam pouco, relativamente, variando de $60 \%$, aproximadamente, na fase embrionária a $64 \%$ na fase de crescimento.

A fase de maturidade mostrou que, exceto no que se refere ao reconhecimento das atividades, pode-se inferir que a empresa é bastante carente no desenvolvimento dos conceitos e práticas em gerenciamento de projetos, deixando clara a distância a ser percorrida visando buscar a maturidade.

A utilização do modelo de Kerzner (2000) mostrou-se bastante interessante, devido à possibilidade em detalhar as variáveis de cada fase. Destaca-se também no trabalho de Kerzner (1999) o instrumento de levantamento de dados que, adequadamente, contribui para a elaboração de diagnóstico. Mais especificamente, o modelo propiciou identificar os elementos de análise, uma vez que o

Figura 1: Caso A, grau de maturidade segundo Kerzner (2000).

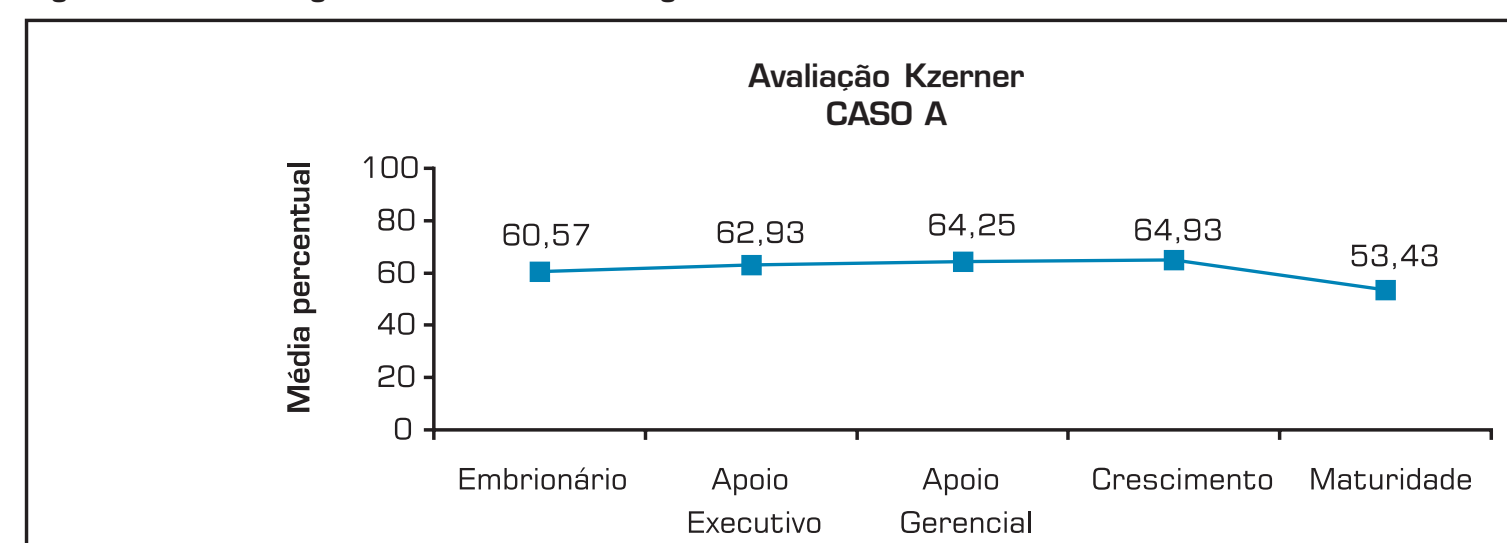

Fases de maturidade nível 2 
levantamento de dados foi pautado na identificação do nível de maturidade.

No estudo deste caso percebeu-se que o modelo de Kerzner (1999) foi útil, mas apresenta alguns pontos que não deixam claras as ações prospectivas, limitando, de certa forma, as possíveis análises da questão gerenciamento de projetos.

O modelo deixou de examinar as seguintes questões, entre outras:

a) competências em gerenciamento de projetos nas suas mais distintas instâncias;

b) constituir um escritório (PMO Project Management Office);

c) construção de uma base de dados, e para isto constituir as ferramentas que irão suportar o gerenciamento dos projetos;

d) desempenho das equipes de projetos;

\section{Estudo do caso B}

A empresa estudada no caso B pertence ao ramo da engenharia da construção com ênfase na execução de empreendimentos complexos e integrados para diversos setores industriais.

Para orientar a análise, foi adotado o modelo do $\mathrm{PMI}^{\circledR}$ Project Management Institute, em desenvolvimento, OPM3 - Organizational Project Management Maturity model. Este modelo, como visto na revisão teórica, está em elaboração e para efeito deste estudo foram considerados os elementos apresentados até o período das entrevistas: junho e julho de 2001. Vale a pena mencionar que foi impossível adotar as inúmeras mudanças ocorridas no modelo utilizado para análise do caso B, até a conclusão deste estudo.

Os resultados obtidos estão expressos na Figura 2.

Os maiores problemas enfrentados pela empresa em relação ao gerenciamento de projetos refletiram-se nas notas médias mais baixas nas dimensões de recursos humanos (42\%, aproximadamente, de atendimento) e de aprendizagem organizacional (em torno de $47 \%$ de atendimento). Não menos importantes, as notas médias das outras três dimensões também refletem carências da empresa no gerenciamento de projetos. As dimensões de metodologias e procedimentos, que apresentaram um grau de 55\%, aproximadamente, de atendimento; apoio organizacional, cujo nível de atendimento ficou em torno de 56\%; e alinhamento estratégico, que teve maior grau de atendimento segundo os entrevistados, com $61 \%$, aproximadamente.

O trabalho proposto pelo grupo de estudo que originou o modelo OPM3 (1999), embora ainda incipiente na época de sua aplicação neste caso, propiciou contribuições relevantes. São elas:

a) existência de requisitos que determinam o posicionamento do projeto na organização;

b) fatores de recursos humanos considerando-se o desenvolvimento de potenciais gerentes de projeto, o treinamento em gerenciamento de projetos, treinamento cruzado, referente às outras áreas, formação de equipes e definição de papéis e responsabilidades;

c) apoio organizacional aos projetos onde se constatou que, apesar da empresa prover amplo suporte para suas unida-

Figura 2: A posição atual e o potencial de melhorias.

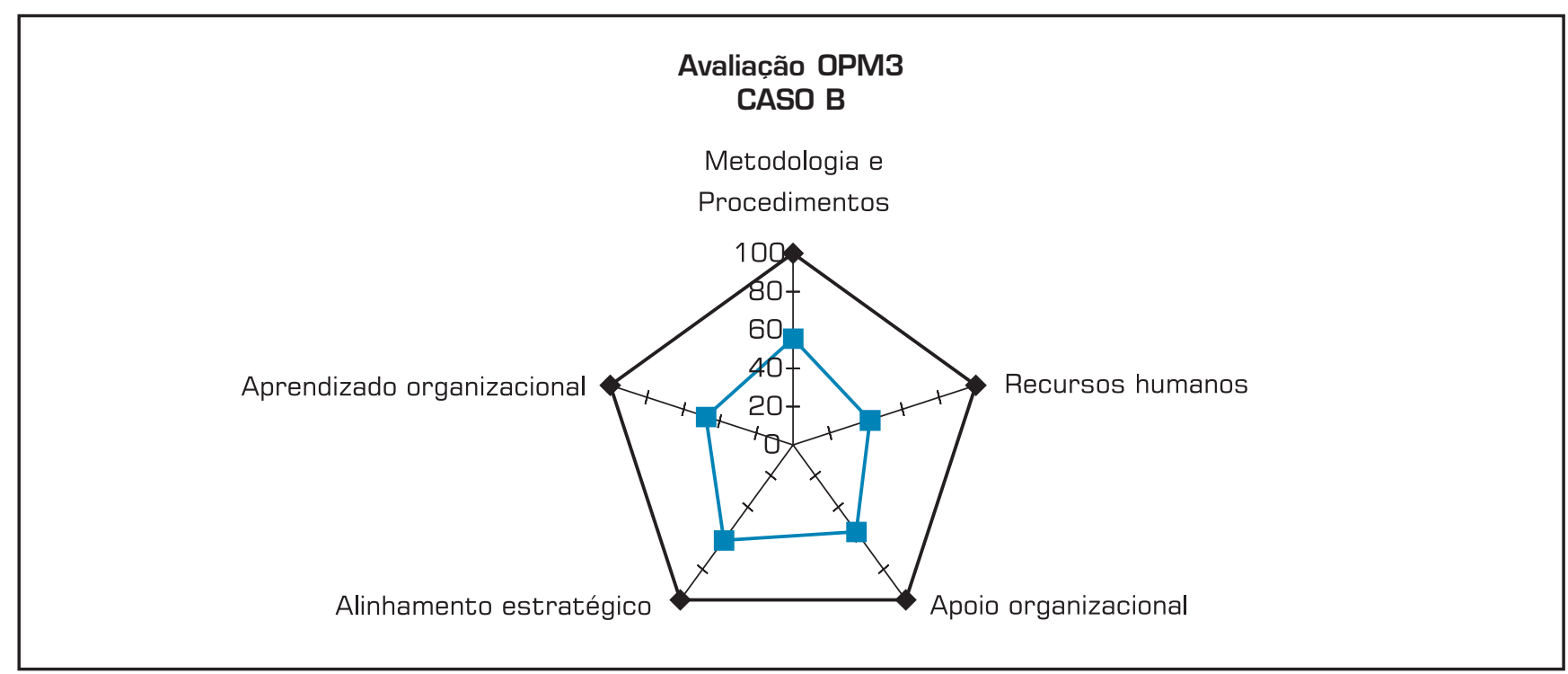

Fonte: Rabechini Jr., et al., 2002. 
des geradoras de receitas, a inexistência de um escritório central de projeto cria ineficiências para a empresa e seus projetos;

d) possibilidade de examinar a interação e interface dos múltiplos projetos desenvolvidos, considerando-se a configuração da carteira de empreendimentos, como questão estratégica; e

e) capacidade de aprendizado em projetos: foram examinados vários elementos, entre eles destacam-se aqueles que se referem à configuração do sistema de controle e, portanto, medições no âmbito do projeto, visando avaliar os resultados efetivos atingidos.

Para o estudo deste caso percebeu-se que o modelo adotado foi útil, mas, ao mesmo tempo, apresenta limitações importantes.

O modelo adotado restringiu-se a desenhar um diagnóstico da atual situação da organização que representou o caso B. A pontuação obtida não revela os caminhos possíveis na direção do gerenciamento de projetos. É apenas uma impressão. Isto pode ser percebido pelos comentários dos entrevistados. Um disse: "falta visão de conjunto em relação ao gerenciamento de projetos na empresa"; outro disse: "falta de conscientização na adoção de práticas integradas de gerenciamento de projetos".

\section{MODELO ANALÍTICO DE INSTITUCIONALIZAC̣̃̃O DE COMPETÊNCIAS E MATURIDADE EM GERENCIAMENTO DE PROJETOS}

O modelo proposto neste estudo foi concebido a partir de três pilares conceituais básicos - estratégia, processos e efetivação da mudança - capazes de dar sustentação às camadas de competências envolvidas na institucionalização de gerenciamento de projetos: indivíduo, equipes e organização. Estas camadas formam uma base conceitual-teórica, apoiada na crença de que a institucionalização de gerenciamento de projetos numa empresa só acontece se forem geradas competências de forma integrada, consistentemente.

O modelo cria uma perspectiva estruturada que representa os valores, variáveis e relacionamentos e reflete o potencial de possíveis ações a serem exploradas como conseqüências analíticas (Figura 3). Tendo-se como base conceitual o modelo proposto, será possível entender ainda o estado da maturidade em gerenciamento de projetos com substratos fornecidos pelas camadas.

Os fatores críticos de sucesso, para os projetos de uma determinada organização, podem ser analisados segundo a perspectiva estratégica e tática. Adotando-se o modelo proposto por Pinto e Slevin (1993), é possível traçar um

Figura 3: Modelo de Competências em Gerenciamento de Projetos

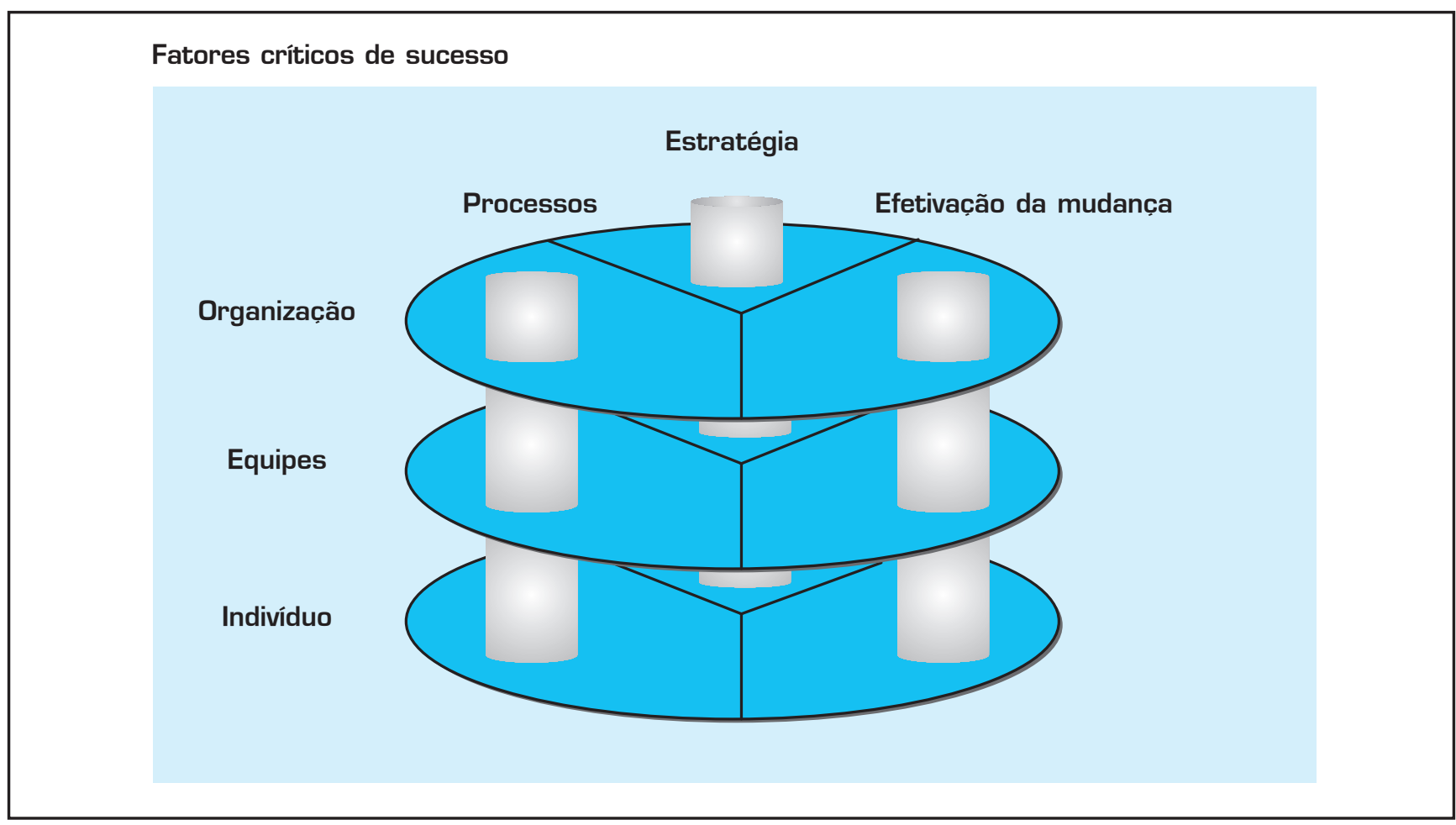


panorama bastante interessante sobre os aspectos de gerenciamento de projetos nas organizações. A aplicação deste modelo foi utilizada por Rabechini Jr. (1999) para avaliar as necessidades em gerenciamento de projetos em instituição de pesquisa. Neste caso, foi possível, através dos resultados obtidos, levantar os principais problemas em administração de projetos na organização, mediante as considerações estratégicas delineadas anteriormente. No entanto, esta foi mais uma aplicação que careceu de apontamentos sobre as competências necessárias em gerenciamento de projetos, ficando clara a existência de oportunidade para avançar na teoria. Uma vez estabelecidas as considerações estratégicas e os fatores críticos de sucesso, cabe então delinear as dimensões centrais do modelo. aconteça, haja um espírito de colaboração e comprometimento com os requisitos de gerenciamento do projeto. Isto significa ter equipes competentes em projetos.

Por fim, a camada da organização, no ímpeto de institucionalizar o gerenciamento de projetos como forma moderna de administração de suas atividades nãorotineiras, deverá estar sensibilizada, disponibilizando recursos, adequando estratégias, divulgando resultados de projetos, etc. Isto é, ser uma organização competente em projetos.

As camadas de competências apóiam-se em distintos pilares, capazes de viabilizar seus respectivos desenvolvimentos. O primeiro pilar se refere aos objetivos estratégicos. Este pilar caracteriza-se por apoiar e estabelecer as diretrizes em relação ao desenvolvimento de gerenciamento de projetos, para todas as competências. Estas diretrizes foram criadas para nortear o desenvolvimento das outras dimensões deste modelo.

Entre os aspectos importantes a serem considerados neste pilar, não exaustivamente, destacam-se:

a) o desenvolvimento de diretrizes que visam estabelecer um escritório de projetos (project office) que, por sua vez dará suporte a toda a organi-

Da camada dos indivíduos, que estão envolvidos em projetos, em linhas gerais, espera-se que eles dominem as técnicas e ferramentas em gerenciamento de projetos, dentro dos parâmetros amplamente divulgados como das restrições de recursos, prazos e custos, característicos de projetos, levando-se em conta, ainda, as exigências de singularidade e empenho. Espera-se que estes indivíduos possuam uma visão bastante abrangente do sentido de governar ou ser governado, mediante a necessidade de alinhamento de projetos às estratégias organizacionais, bem como do desenvolvimento das habilidades gerenciais e da capacidade em aplicar as técnicas e ferramentas de gerenciamento de projetos. Neste aspecto buscou-se identificar ações que elevem o grau de competência do indivíduo em relação a suas capacidades gerenciais, de conhecimento do negócio e de gerenciamento de projetos. Em suma, isto significa ter indivíduos competentes em projetos.

As equipes, no âmbito dos projetos, devem ser próativas em buscar resultados, através de uma orientação voltada às tarefas e atividades. Neste aspecto, buscou-se planejar ações visando torná-las aptas ao desenvolvimento de comprometimento com a agenda do projeto, bem como com orçamento, gestão dos riscos, com a qualidade, entre outros aspectos. Espera-se que, também, para que isto zação no que se refere à gestão de projetos;

b) a carreira do gerente de projeto e, como consequiência, sua remuneração profissional;

c) carteira de projetos como opção gerencial de organização e priorização de projetos na organização;

d) a capacitação das equipes de projetos.

O segundo pilar se refere aos processos. Este pilar visa o desenvolvimento das funções que integram os requisitos de gerenciamento de projetos na empresa para as três camadas propostas. Normalmente este pilar caracteriza a metodologia de gerenciamento de projetos a ser empreendida na empresa. Este pilar, na verdade, dará suporte ao conjunto de estratégias definidas pela organização no que tange ao gerenciamento de projetos.

O terceiro pilar se refere à mudança prescrita, decorrente das estratégias configuradas e do desenho dos processos. Este pilar representa os elementos necessários para se configurar o entendimento do gerenciamento da mudança organizacional e de suas barreiras, ocasionadas durante implantação da gestão por projetos. Este pilar, para efeitos de análise, deverá contemplar os indicadores de desempenho dos projetos e seus respectivos gerenciamentos, considerando-se a possibilidade de analisar as competências das três camadas sugeridas. 


\section{PROPOSTA DE VALIDACÃO DO MODELO - CASO C}

$\mathrm{O}$ caso $\mathrm{C}$ foi estudado a partir de uma empresa brasileira pertencente ao setor de transportes aéreos.

A análise dos resultados, quando configurada a partir do modelo proposto, revelou a existência de uma série de carências, muitas vezes, não percebidas por abordagens tratadas na literatura teórica, revisada neste estudo.

A configuração dos resultados perante o modelo foi feita através de uma proposta de enquadramento utilizando a matriz de maturidade como ferramenta auxiliar da análise. Considerando-se os pilares de estratégia e processos do modelo como indicadores, configuraram-se quatro cenários específicos (Figura 4). Assim, quando no levantamento de dados sobre os indicadores de estratégia e processo nota-se baixo nível de atendimento, configura-se o primeiro cenário - iniciante, ou seja, diz-se que as dimensões enquadradas aqui têm pouca competência e maturidade.

O segundo cenário é aquele em que se enquadram os casos onde os indicadores de estratégia atingem níveis considerados de atendimento. Neste cenário sabe-se que as chances de se conseguir os resultados dos projetos existem, entretanto de forma intuitiva.

Já no terceiro cenário, os níveis elevados de atendimento ficam por conta dos indicadores de processo. Neste cenário há a representação que reflete falta de alinhamento, pois os resultados (estratégia) não estão sendo adequadamente percebidos.

Por fim, configura-se o cenário da maturidade, no qual são percebidos atendidos tanto os indicadores de estratégia quanto os de processo.

Olhando o caso $\mathrm{C}$ a partir destes cenários e fazendo-se comparações com os modelos existentes na literatura, adotados neste estudo, sob o prisma dos indivíduos, notouse uma discrepância bastante significativa. Foi possível perceber que as carências não tratadas pelos modelos da literatura teórica ficaram nítidas quando examinadas no contexto dos pilares conceituais deste modelo. Tudo leva a crer que a dimensão do indivíduo, quando analisada pelo modelo, mostra uma perspectiva bastante pessimista, ou seja, considerando-se a matriz de maturidade, as carências percebidas apontam para o cenário iniciante.

$\mathrm{Na}$ camada das equipes, a dimensão menos tratada diretamente pelos modelos visitados na revisão teórica, verificou-se um cenário não tão pessimista, uma vez que os resultados, no caso $\mathrm{C}$, apresentam-se adequados. $\mathrm{Ou}$ seja, os projetos têm dado, em linhas gerais, contribuições para o desenvolvimento da área e da organização estudada. No caso $\mathrm{C}$, isto pôde ser percebido de forma mais explícita, uma vez que a área de tecnologia de informação, examinada no estudo, desenvolve projetos cujos produtos ou serviços atendem as áreas estratégicas da empresa, atingindo resultados comprovados pela sua manutenção no setor e mesmo crescendo em termos de investimentos. Os projetos desta área da organização têm obtido resultados expressivos, o que levou à constituição de uma vice-presidência na empresa.

$\mathrm{Se}$, de um lado, o modelo proposto ajudou a revelar a existência de resultados concretos obtidos pelas equipes de projetos, por outro, nota-se de forma evidente a ausência de formalização no aumento de capacitação das mesmas.

Na camada da organização, a mais tratada nos modelos teóricos, foi possível extrair elementos relevantes que apontaram para o estabelecimento de ações na direção de gerenciamento de projetos. No entanto, os resultados não mostraram claramente o volume de medidas a serem delineadas, dando a impressão, equivocada, que a organização apresenta-se em situação bastante confortável em relação ao gerenciamento de projetos. Além dos processos e mesmo antes deles, o modelo proposto aponta para a necessidade de estabelecimento de estratégias em termos de gerenciamento de projetos para a organização.

$\mathrm{O}$ enquadramento da análise feita através do modelo proposto pode ser percebido pela Figura 4.

\section{CONSIDERACÕ̃ES FINAIS}

Este estudo apresentou um modelo conceitual analítico no sentido de subsidiar as empresas para se estruturar e desenvolver competências visando atingir maturidade em gerenciamento de projetos. O modelo apresentado, constituído de camadas e pilares conceituais, integrados, apresentou ainda elementos suficientes para responder à principal questão da pesquisa que deu origem a este trabalho: como as empresas podem se estruturar para desenvolver competências visando atingir maturidade em gerenciamento de projetos? Rumo à maturidade em gerenciamento de projetos a organização deve, para poder percorrer este caminho, considerar camadas (indivíduo, equipes e organização) de desenvolvimento de competências, além das questões estratégicas, dos fatores críticos de sucesso em projetos e constituir uma perspectiva estruturada, através do delineamento de estratégias, processos e efetivação das mudanças. O estudo, neste aspecto, apontou para resposta de mais uma questão: quais as dimensões relevantes consideradas no caminho a ser percorrido.

Cabe, então, pontuar as conclusões mais específicas: a) Os modelos de maturidade, em geral, vêm no sentido de auxiliar tanto os pesquisadores, quanto os practitioners e management, na tentativa de estabelecer uma visão holística sobre gerenciamento de projetos nas organizações. No entanto, verificou-se nos casos que os modelos 
analisados, em geral, não se mostram adequados, pois não foram exaustivos na configuração de elementos para análise, deixando, portanto, muitas lacunas a serem preenchidas.

$\checkmark$ Os modelos utilizados apresentam elementos bastante importantes, mas não exaustivos.

$\checkmark$ Torna-se extremamente difícil abordar, num modelo, todas as variáveis envolvidas na institucionalização de projetos numa organização.

$\checkmark$ Estas observações apontam para a necessidade de se ter um modelo abrangente das questões de gerenciamento de projetos.

b) A análise (de dados secundários) de documentos das organizações estudadas foi tão importante quanto as entrevistas, pois, em relativos graus, ajudaram a comprovar ou reprovar as afirmações primárias;

$\checkmark$ Embora os modelos adotados da literatura técnica fornecessem, em alguns casos, questionários de levantamento de dados, eles não conseguem, de forma prática, estabelecer todas as variáveis de um problema tão complexo como o da institucionalização de gerenciamento de projetos nas organizações.

c) $\mathrm{O}$ modelo proposto, embora não-evolutivo, foi útil para entender o panorama das carências da organização em gestão de projetos;

$\checkmark \mathrm{O}$ modelo proposto mostrou, de forma agregada, uma amplitude considerável de variáveis relevantes na confi- guração de um plano de institucionalização de gerenciamento de projetos nas organizações.

$\checkmark$ O modelo, assim, proporcionou uma visão holística da questão da institucionalização de gerenciamento de projetos.

$\checkmark$ Foi possível, através do modelo, estabelecer uma análise sobre pressupostos sobre a causa da institucionalização via desenvolvimento de competências e estabelecimento de maturidade - aqui, sim, de forma evolutiva.

d) O modelo proposto mostrou-se adequado à identificação de competências nas dimensões estudadas: indivíduo, equipes de projeto e organização.

$\checkmark$ Estas camadas são amplas e, portanto, requerem elaboração de um estudo detalhado para a sua ideal configuração.

$\checkmark$ O modelo, neste sentido, não apresenta instrumento de levantamento de dados, mas, na verdade, possibilita o uso de outras configurações já desenvolvidas na literatura técnica, acrescido, obviamente, da necessidade em buscar informações internas à organização por meio de entrevistas e análise documental.

$\checkmark$ Neste aspecto, observa-se a incidência de uma espécie de meta-modelo, que fornece elementos essenciais na descoberta de variáveis relevantes à institucionalização de gerenciamento de projetos nas organizações. Assim, complementa outros modelos e não os substitui.

e) Quando se focaliza a organização e suas competências, abrem-se possibilidades de se discutir temas centrais como: definição de estratégias e processos técnicos e

Figura 4: Matriz de maturidade: cenários de indicadores de projetos e gerenciamento de projetos do caso C.

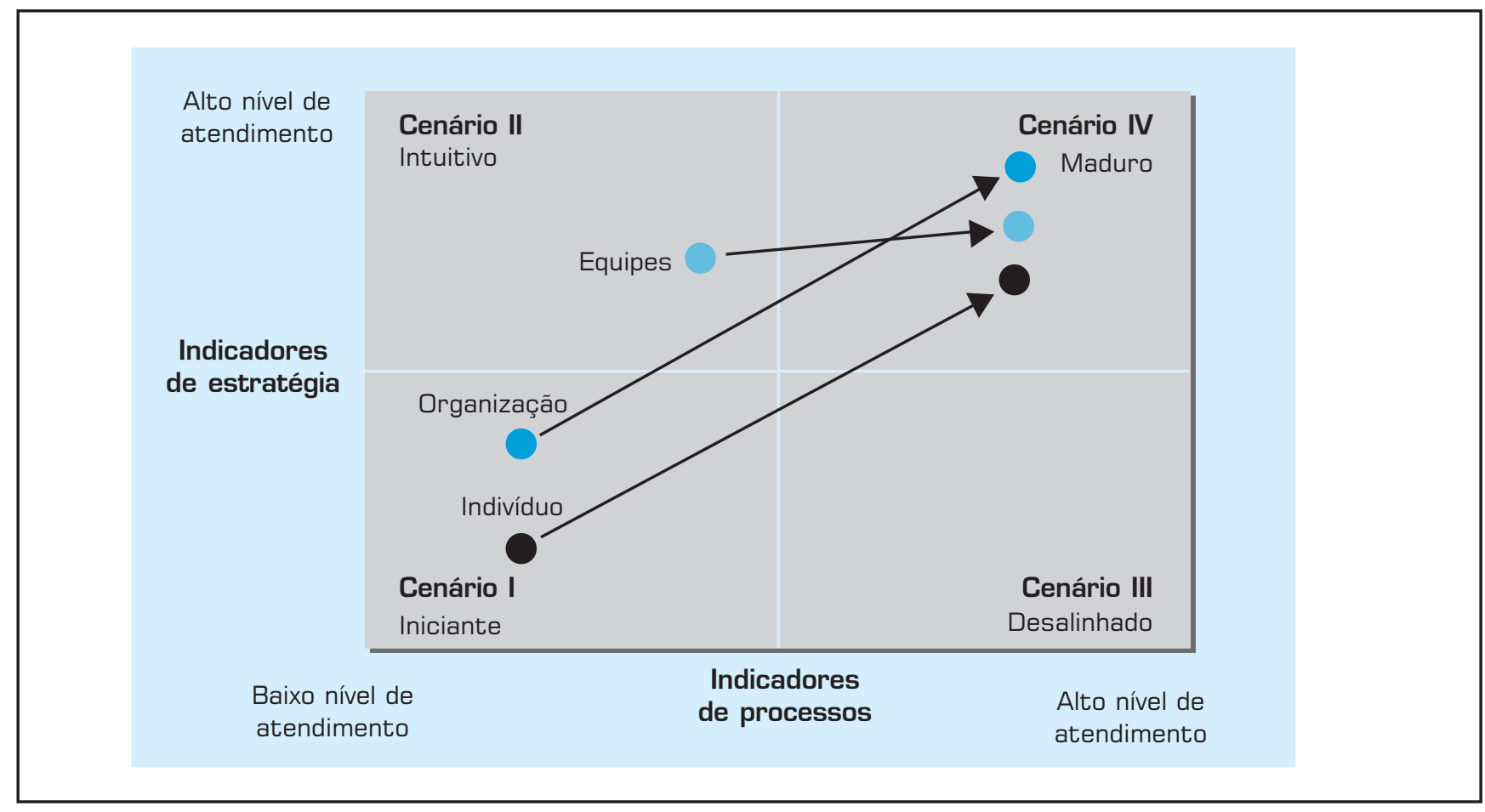


gerenciais envolvendo as áreas de conhecimento em gerenciamento de projetos. Neste aspecto cabe mencionar a possibilidade de identificar os processos pelos quais a organização evolutivamente vai optar em relação ao gerenciamento de projetos.

$\checkmark$ Abrem-se também possibilidades de discussão em temas não centrais como: gestão de carteira de projetos, gestão de programas, expandindo assim os limites de gerenciamento de projetos na organização, na medida em que se percebe maior grau de competência e maturidade.

f) A configuração final do modelo validada pelo último caso não se apresentou, evidentemente, de forma detalhada e, portanto, exaustiva.

$\checkmark$ Assim, conforme a adoção deste modelo pelos practitioners em gerenciamento de projetos interessados nas competências e maturidade, abrem-se possibilidades de acrescentar um maior grau de detalhe em suas camadas e pilares apresentados, viabilizando assim um refinamento contínuo.

A contribuição do trabalho desenvolvido, na opinião do autor, foi oferecer uma nova abordagem para a compreensão do processo de mudança organizacional na direção da institucionalização de gerenciamento de projetos.

Como limitações do estudo destacam-se as questões metodológicas do estudo de caso: a) restrição do pesquisador aos dados das organizações; e b) o número de entrevistados em cada caso. Estas limitações da metodologia implicam, pela sua natureza, tornar impróprias generalizações acerca dos resultados da pesquisa.

\section{Artigo recebido em 06/02/2004 Aprovado para publicação em 11/02/2005}

\section{- Referências Bibliográficas}

CLELAND, D.I. Project management: strategic design and implementation. 3 ed. New York: McGraw Hill, 1999.

CLELAND; IRELAND, L.R. Gerência de projetos. Rio de Janeiro: Reichmann \& Affonso, 2002.

FLEURY, A.; FLEURY M.T.L. Estratégia empresariais e formação de competências: um quebra-cabeça caleidoscópio da indústria brasileira. São Paulo: Atlas, 2000.

FRAME, J.D. Project management competence: building key skills for individuals, teams and organizations. San Francisco: Jossey-Bass, 1999.

KERZNER, H. Strategic planning for project management using a project management maturity model. New York: John Wiley \& Sons, 1999.

Applied project management best practices on implementation. New York: John Wiley \& Sons, 2000.
KING, W.R. The role of projects in the implementation of business strategy. In: CLELAND, D.I.; KING, W.R. Project management handbook. New York: Van Nostrand Reinhold, 1983.

LE BOTERF, G. L'ingénierie des competences. Paris: Editions d'organization, 1988.

LE BOTERF, G. De la Compétence. Paris: Les Editions d'Organization, 1994.

MAXIMIANO, A.C.A. O gerente de projetos: um ator com vários personagens. Revista de Administração. v. 23, n. 2, p. 93-8, abr.jun. 1988.

PINTO, J.K.; SLEVIN D.P. Critical success factors in effective project implementation. In: CLELAND, D. I.; KING, W.R. Project management handbook. New York: Van Nostrand Reinhold, 1983.
PINTO, J.K.; SLEVIN, D.P. Critical success factors. In: PINTO, J.K. Project management handbook. San Francisco: Jossey-Bass, 1998.

PROJECT MANAGEMENT INSTITUTE PMI - Organizational project management maturity model (OPM3). Disponível em: < http://www.pmi.org/ opm3>, <http://www.pmi.org/ standards/pmcapabilities.htm, $>$. Acesso em: 1999.

A guide to the project management body of knowledge (PMBOK Guide). Upper Darby, PA, 2000

RABECHINI JR., R. A importância das habilidades do gerente de projeto. Revista de Administração, v. 36, n.1, p.92-100, jan./mar. 2001 .

RABECHINI JR.; CARVALHO, M. M. Concepção de um programa de gerência de projetos em instituição de pesquisa. Revista Valenciana Dèstudis Autonòmics, v. 1, n. 20, p. 1, 1999.
RABECHINI JR.; MARQUES JR., L.J. TOLEDO, N. N. Grau de maturidade em gestão de projetos. In: Congreso Ibero Americano de Gerencia de Proyectos, 3, Memórias em CD do Capítulo Venezuela do PMI Project Management Institute, Caracas, 2002.

SCHLICHTER, J. PMI's. Organizational project management maturity model emerging standards. In: Project Management Institute Annual Seminars \& Symposium, Nashville 2001. Proceedings. Nashville, PMI, 2001.

SOFTWARE ENGINEERING INSTITUTE (SEI). The capability maturity model for software (version 2B). Carnegie: Carnegie Mellow University, 1997

THAMHAIN, H.J. Team building in project management. In: CLELAND, D.I.; KING, W.R. Project management handbook. New York: Van Nostrand Reinhold, 1983.

\section{- Sobre os autores}

\section{Roque Rabechini Jr.}

Doutor pela Escola Politécnica da USP, Consultor de Empresas.

Endereço: Av. Prof. Almeida Prado, 128 - 05508-900 - C. Universitária - São Paulo, SP

E-mail: roquejr@usp.br

\section{Marcelo Schneck de Paula Pessôa}

Prof. do Depto. de Engenharia de Produção da Escola Politécnica da USP.

Endereço: Av. Prof. Almeida Prado, 128 - 05508-900 - C. Universitária - São Paulo, SP

E-mail: mpessoa@usp.br 